\title{
Application of Synthetic Storm Technique for Diurnal and Seasonal Variation of Slant Path Ka-Band Rain Attenuation Time Series over a Subtropical Location in South Africa
}

\author{
J. S. Ojo and P. A. Owolawi \\ Department of Electrical Engineering, Mangosuthu University of Technology, P.O. Box 12363, Jacobs, Durban 4026, South Africa \\ Correspondence should be addressed to J. S. Ojo; josnno@yahoo.com
}

Received 3 March 2014; Revised 16 August 2014; Accepted 20 August 2014

Academic Editor: J. S. Mandeep

Copyright (C) 2015 J. S. Ojo and P. A. Owolawi. This is an open access article distributed under the Creative Commons Attribution License, which permits unrestricted use, distribution, and reproduction in any medium, provided the original work is properly cited.

\begin{abstract}
As technology advances and more demands are on satellite services, rain-induced attenuation still creates one of the most damaging effects of the atmosphere on the quality of radio communication signals, especially those operating above $10 \mathrm{GHz}$. System designers therefore require statistical information on rain-induced attenuation over the coverage area in order to determine the appropriate transmitter and receiver characteristics to be adopted. This paper presents results on the time-varying rain characterization and diurnal variation of slant path rain attenuation in the Ka-band frequency simulated with synthetic storm techniques over a subtropical location in South Africa using 10-year rain rate time-series data. The analysis is based on the CDF of one-minute rain rate; time-series seasonal variation of rain rate observed over four time intervals: 00:00-06:00, 06:00-12:00, 12:00-18:00, and 18:00-24:00; diurnal fades margin; and diurnal variation of rain attenuation. Comparison was also made between the synthesized values and measured attenuation data. The predicted statistics are in good agreement with those obtained from the propagation beacon measurement in the area. The overall results will be needed for an acceptable planning that can effectively reduce the fade margin to a very low value for an optimum data communication over this area.
\end{abstract}

\section{Introduction}

Satellite communication services continue to grow as more users kept demanding for the usage. However, such services at millimeter wave frequencies can be affected by huge rain attenuation. At frequencies beyond $10 \mathrm{GHz}$, rainfall is one of the important atmospheric parameters (hydrometeors) which causes signal degradation along both terrestrial and satellite tracks [1]. In recent times, the Synthetic Storm Techniques (SST) has been identified to be a powerful and accurate tool that can produce all the necessary statistics of rain attenuation based on the time series of rain rate $R(\mathrm{~mm} / \mathrm{h})$ at the site, at any frequency and polarization, and for any slant path above about $10^{\circ}$ whenever a real radio link is not available [2-7]. It therefore shows that whenever there is information for time-series prediction of rain attenuation, fade countermeasure techniques like adaptive control of signal power, coding, and data rate can be implemented effectively. The limitation of experimental data for rain attenuation to develop channel model is of concern for most locations in the tropical and subtropical region; however, large data of rain rate are much available in most of the meteorological stations worldwide, although with different integration time.

In this paper, one-minute time-series rain events were converted into attenuation time series for Ka-band signal at Durban, a subtropical location in South Africa, using SST. This work is carried out in the first place due to the deficiency of rain attenuation data and models for this region which had run into the difficulty in implementing rain-resistant systems in microwave and millimeter wave bands in the region and secondly due to the prevailing climatic condition in terms of higher annual precipitation in the region as compared to other locations in South Africa [8]. An attempt is also made to test the validity of the result obtained based on the eventwise with propagation measurement. 


\section{Climate Characteristics of the Study Location and Data Bank}

The study location is Durban (altitude $8 \mathrm{~m} ; 29^{\circ} 97^{\prime} \mathrm{S}, 30^{\circ} 95^{\prime} \mathrm{E}$ ) with a mild and subtropical climate having an average of 320 days of sunshine in a year. The city belongs to the coastal savannah region located along the Eastern frontiers of the Republic of Southern Africa. It has an average annual precipitation of over $1000 \mathrm{~mm}$ and is unarguably regarded as one of the wettest cities in South Africa [8]. Like every other part of South Africa, Durban's seasons can be classified into four, namely, summer, which occurs from mid-October to mid-February with temperatures often rising above $30^{\circ} \mathrm{C}$, the autumn, which is between mid-February and April, winter, which occurs from May and lasts till July, and spring, which occurs from August to mid-October. Generally, Durban experiences warm and wet summers and mild, moist to dry winters. The study therefore attempts to establish local first order statistical rain attenuation using SST to mitigate the severe fade experienced at higher frequency bands due to the huge presence of hydrometeors in this region.

The data utilized for this work is obtained from South Africa Weather Services (SAWS) with the help of automated rain gauge, which is a tipping bucket rain gauge with a $200 \mathrm{~mm}$ standard funnel opening. The rain collected with the aid of the standard funnel is then converted into drops of approximately equal sizes. The number of drops collected every 10 seconds is electronically counted and then averaged over the specified integration time. The automatic gain control (AGC) voltage of each channel is sampled continuously and stored in digital mode, with the date and time of each tipping of the rain gauge. The rain gauge calibration is maintained by periodic cleaning of the capillary. Based on our previous work [9], the raw rain rate time series have been processed to provide the convectional one-minute rain rate time series from the ten years achieved rain rate data (2001-2011) of the SAWS. Other details of measurement methodology in the present study are available in [9]. The one-minute time-series rain rate data generated are then used to estimate attenuation time-series statistics using the SST method of converting rain rate/time profiles recorded at a point to rain rate/distance profiles with the aid of the translational velocity of the rain pattern that is estimated as the wind speed $[7,10]$.

\section{Synthetic Storm Techniques (SST)}

The so-called SST have one of the major advantages of employing local time series with the assumption of duallayer representation of precipitation to include the additional attenuation attributable to the melting layer. It may also reproduce dynamic characteristics of rain fade and power spectra. Recent studies show that SST have been applied to estimate multivariate probability distributions of rain attenuation simultaneously exceeded in distant sites, information that is useful to design satellite systems with a common onboard resources $[11,12]$. The robustness of the SST model had also been proved by some researchers over the world in terms of yearly cumulative distribution function (CDF), among these are the works of $[2,13,14]$. The method (SST) described the value of rainfall as a function of the length where that rain moved on the line because of the wind with particular speed. It also involves some local parameters like the position of the receiver, elevation angle, and rain cell speed. The application of the SST also depends on some assumptions taken in the formulation: the advection velocity of rain cell is assumed to be constant and in the direction of the projection of the link on the ground [15]. In other words, rain attenuation statistics on a hypothetical link passing through or near from a site can be determined by segmenting the links, with each segment to be equal to the travel distance from the rain structure as it is burned out by the wind during one sampling time of the measurement of the rainfall rate. During every sampling period, the attenuation by rain is estimated as the summation of specific attenuation $(\mathrm{dB} / \mathrm{km})$ multiplied by the length of the segment. This can be expressed as

$$
\begin{gathered}
A_{m}=\sum_{j=0}^{n=1} k R_{m-j}^{\alpha} \Delta L_{j}(\mathrm{~dB}) \\
\Delta L=V_{t} \times t(\mathrm{~km}),
\end{gathered}
$$

where $k$ and $\alpha$ are coefficient, which is frequency dependent together with the depolarization of the wave, temperature, and drop size distribution-relating rainfall rate to the specific rain attenuation $(\mathrm{dB} / \mathrm{km}), R$ is the $m$ th sample of rain rate measurement, $m$ is the number of segments making up the link, $\Delta L$ is the length of the $m$ th segment of the link, $V_{t}$ is the wind on a line, and $t$ is the integration time, one minute. Detailed physical and mathematical fundamental are described at length by Matricciani [2] and Drufuca [15] and therefore are not repeated here.

In order to estimate the time-series rain attenuation using SST, we have used different storm speeds, $v$, between 1 and $16 \mathrm{~m} / \mathrm{s}$ as obtained from meteorological measurements in order to show the sensitivity of this parameter to the SST model. The vertical structure of the precipitation medium has been modeled with two layers of different depths: layer $A$ starts from the ground with the existence of rain (raindrops with a water temperature of $20^{\circ} \mathrm{C}$ ) and layer $B$ with melting hydrometeors at $0^{\circ} \mathrm{C}$ [2] as depicted in Figure $1 . R_{A}$ is the homogeneously falling rain at layer $A$, while $R_{B}$ is the apparent rain rate of layer $B$ dominated by ice, where [15]

$$
R_{A}=3.142 R_{B}
$$

The parameters ( $k$ and $\alpha$ ) necessary to relate the rainfall rate to the specific rain attenuation $(\mathrm{dB} / \mathrm{km})$ are calculated for water temperature of $20^{\circ} \mathrm{C}$ and law parsons drop size distribution as stated by the ITU-R [16] and for the $0^{\circ} \mathrm{C}$ by [17]. The recent ITU-R rain height has also been taken into account [18].

The input parameters needed by the SST model in our region are considered as follows. The altitude above sea level of the earth station is $H_{S}=0.008 \mathrm{~km}$. According to [18] the height of the precipitation (rain and melting layer) above sea 


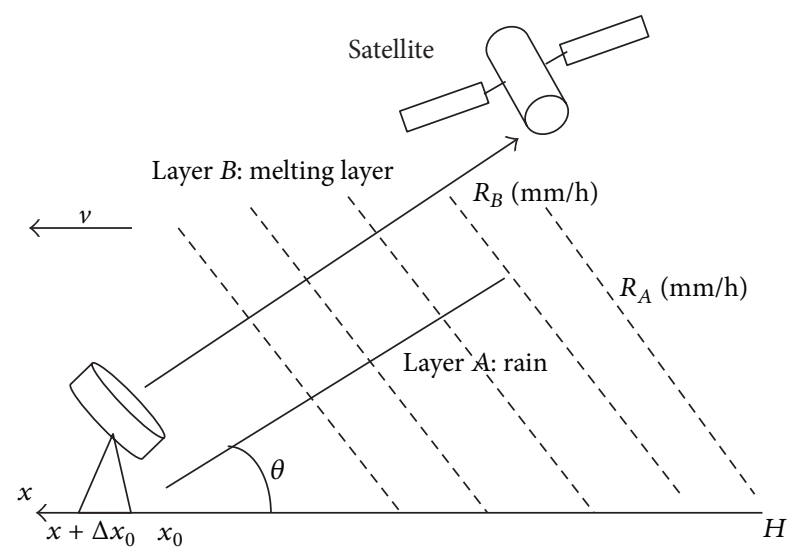

FIGURE 1: Schematic diagram of rain structure for synthetic storm techniques.

level $H_{B}$ depends on the latitude $(\phi)$ of the Earth station and can be expressed as

$$
\begin{gathered}
H_{B}=5, \quad \phi<23^{\circ} \\
H_{B}=5-0.075\left(\phi-23^{\circ}\right), \quad \phi \geq 23^{\circ} .
\end{gathered}
$$

From the simulation, $H_{B}=4.4825 \mathrm{~km}$. Also, the thickness of the melting layer $(h)$ is considered to be $0.4 \mathrm{~km}$ regardless of the latitude. The Intelsat 17 (IS-17) satellite (geostationary at $66^{\circ} \mathrm{E}$ ) with its service footprint links at an elevation angle of $38.4^{\circ}$ is assumed.

Hence the specific attenuation at a given point is converted into signal attenuation $A\left(x_{0}\right)$ for a satellite path as it is in our case using the following expression:

$$
\begin{aligned}
A\left(x_{0}\right)= & k_{A} \int_{0}^{L_{A}} R^{\alpha A}\left(x_{0}+\Delta x_{0}, \xi\right) d \xi \\
& +k_{B} r^{\alpha B} \int_{L_{A}}^{L_{B}} R^{\alpha B}\left(x_{0}, \xi\right) d \xi,
\end{aligned}
$$

where $\xi$ is the distance measured along the satellite path. According to [17] the height above sea level, $H_{A}$, of the upper limit of layer $A$ is given by

$$
H_{A}=H_{B}-h=4.0825 \mathrm{~km} \text {. }
$$

The radio path lengths are calculated using

$$
\begin{aligned}
& L_{A}=\frac{H_{A}-H_{S}}{\sin (\theta)}=6.5563 \mathrm{~km}, \\
& L_{B}=\frac{H_{B}-H_{S}}{\sin (\theta)}=6.9407 \mathrm{~km},
\end{aligned}
$$

where $\theta$ is the link elevation angle; $\Delta x_{0}$ is a shift to account for the fact that the radio path exists layer $B$ at $x_{0}+\Delta x_{0}$ and can be expressed as [14]:

$$
\begin{gathered}
\Delta x_{0}=\Delta L \cos (\theta)=\frac{h}{\tan (\theta)}, \\
\Delta L=L_{B}-L_{A}=\frac{h}{\sin (\theta)} .
\end{gathered}
$$

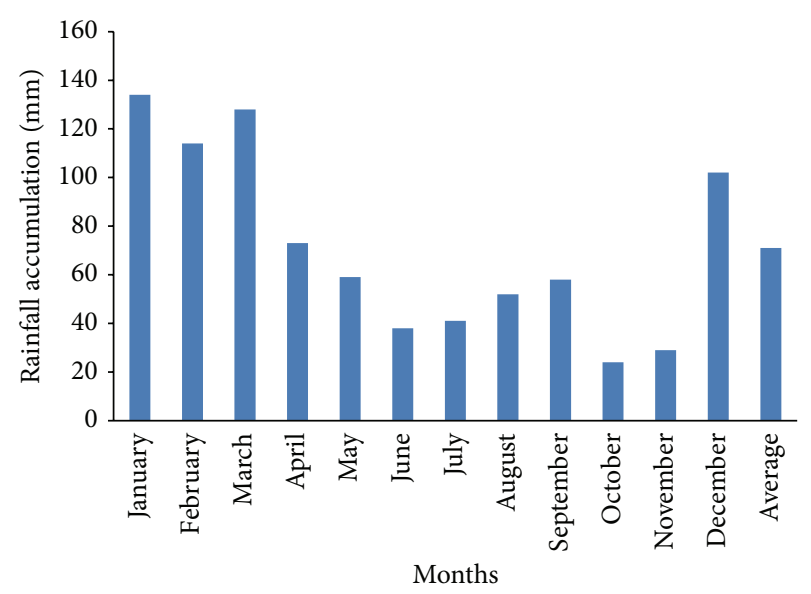

FIGURE 2: Average monthly accumulation over a period of 10 years.

Each of the attenuation time series is then obtained from the corresponding time-series rain rate for every observation.

Hence, our SST are derived based on the above expressions by applying the Fourier transforms theory and taking into consideration some of the assumptions.

\section{Results and Discussion}

In this section we discuss the detailed statistical analysis of the observed results and their applications for radio communication in the region.

4.1. Average Monthly Rainfall Accumulation and CDF of OneMinute Rain Rate. Figure 2 shows the mean monthly rainfall accumulation over 10 years for the study location (Durban). The location belongs to the coastal savannah region and experiences regular rainfalls all year long with the maximum rainfall accumulation during the summer (January) while the minimum average rainfall accumulation of about $24 \mathrm{~mm}$ could be observed during the winter months. The variation in the monthly rainfall accumulation is as a result of the contrast in temperature between the warm south-flowing Mozambique-Agulhas current and the cold north-flowing Benguela. The analysis shows that the wettest months are between December and March. This is in agreement with the previous studies by $[19,20]$ where they showed that Durban (east coast) has higher rainfall than Lamberts Bay (west coast). This analysis is very important for determining the quality objectives of telecommunication networks.

Figure 3 presents the cumulative distributions of oneminute rain rate and ITU-R estimated values. Generally, we observed a good fit at higher percentages of time with low rain rates (lower than $20 \mathrm{~mm} / \mathrm{h}$ ). However, considerable differences between the measured data and the ITU-R are obtained at lower percentages of time with large rain rates (greater than $40 \mathrm{~mm} / \mathrm{h}$ ). To be specific based on the recommendation of ITU R P 311-12, [21], ITU rain model underestimated the measured data with relative errors between -37 and $-9 \%$ at exceedance probability levels $0.1<P \geq 0.001 \%$. The results are presented to access the relationship between 


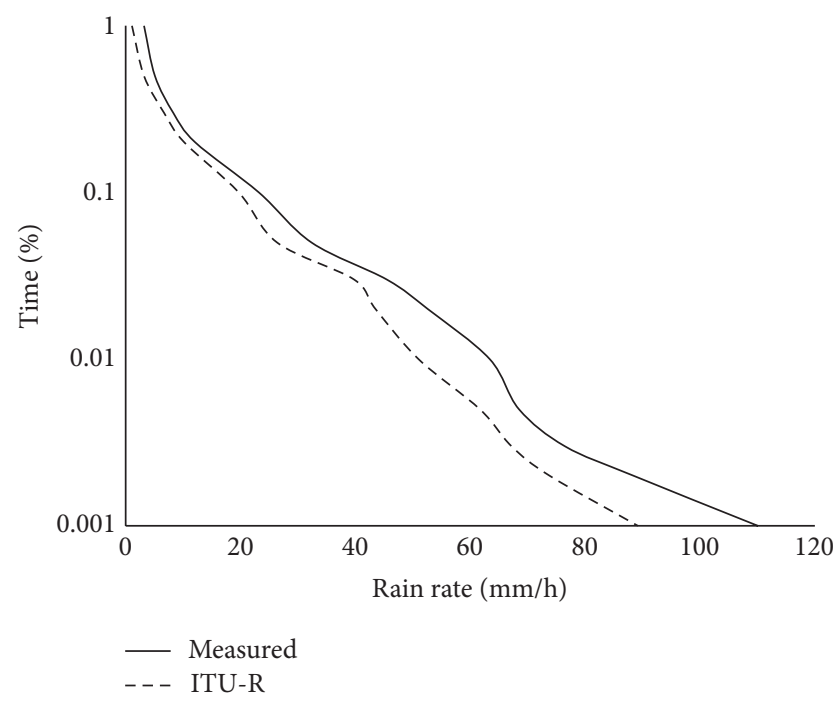

FIgURE 3: Cumulative distribution of one-minute rain rate.

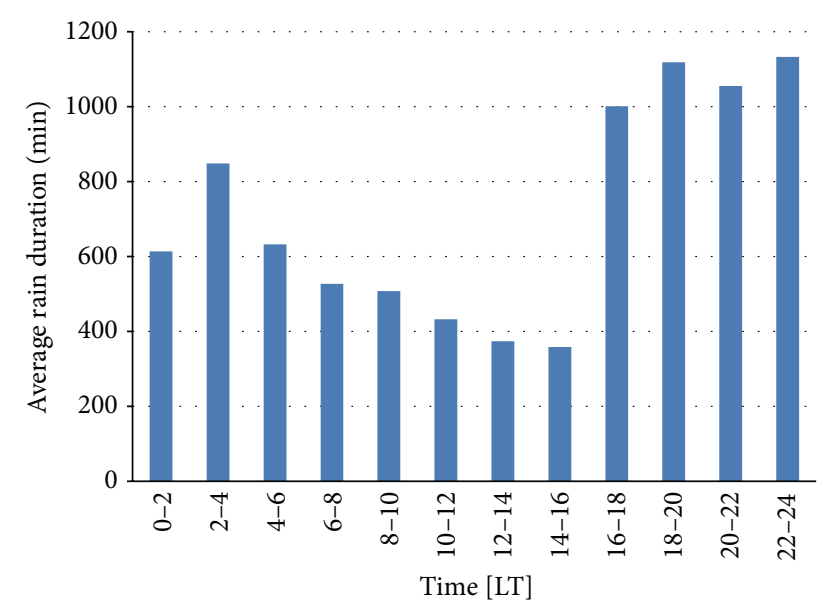

FIGURE 4: Distribution of average rain duration over the observed period.

ITU-R recommendations [22] for this region and the measured results.

4.2. Diurnal and Seasonal Variation of Rain Rate. Figure 4 presents the diurnal rain patterns over the observation period. We have categorized the duration over 24 hours in a day with $2 \mathrm{hrs}$ nonoverlapping time intervals $(00-02,02-$ $4, \ldots, 22-24)$. The total rain duration is obtained by dividing the year of observation (10 years) to arrive at the relative distribution of rain duration in a year. We observed that the probability of rain occurrence as well as rain intensity differs from time to time. For instance, in this coastal region, the result shows that rainfall is comparatively less in the afternoon hours around 06 to 3 pm local time (06:00-15:00 GMT) than in the evening and early morning hours. This is contrary to reports by Das et al. [23] that maximum rain occurs at afternoon over the Indian land (also a tropical location) mass compared to evening hours.
Figures $5(\mathrm{a})-5(\mathrm{~d})$ also present the long term rain rate seasonal exceedance probability at different hours of the day. In this case, the $24 \mathrm{hrs}$ are divided into 6 blocks of 4 hrs duration and rain rate exceedance is then presented for each segment seasonwise. For each hour of the day, summer months provide significantly higher rain rate than every other season, while spring months present significantly less rain rate. According to Figure 2, January happens to be the wettest month that contributed greatly to the summer precipitation as regards these hours. We also see that 00:00-06:00 GMT and 18:00-24:00 GMT hrs provide more rain rate compared to the other hours of the day. In fact, the lesser rain rate occurs between the hours of 06:00 and 12:00 GMT. This is in agreement with the result earlier obtained in Figure 4 . The effect observed in our work is a bit different with the earlier result by Alonge and Afullo [19] in the same region, where they observed highest seasonal value of rain rate at $0.01 \%$ unavailability of time during the autumn season followed by the seasons of summer, spring, and winter season. In our case, we observed a gradual increase of rain rate values from 1 to $0.001 \%$ unavailability of time for summer season followed by the seasons of autumn, winter, and spring. The differences might be due to the limitation of the number of years they use (2 year) as well as categorizing our seasonal trend on a diurnal basis. This analysis is important for system designers since faded margin needed to be utilized for a respective period will depend on the amount of rain rate which invariably determines the attenuation.

4.3. Validating SST Model with Experimental Data. In this subsection, we present the synthesized rain attenuation obtained using the time-series rain rate and make comparison with the experimental propagation data. The predicted attenuation results were tested against experimental propagation data carried out in the year 2004 at the University of Kwazulu-Natal, Durban. The Ka-band modulated signal, horizontally polarized at a frequency of $19.5 \mathrm{GHz}$ level, has been received by an offset feed valuline WR42/R220 parabolic antennae of diameter $0.6 \mathrm{~m}$ with an elevation angle of $30.980^{\circ}$. Detailed characteristics of the setup link are reported in [24].

In Figure 6, the synthesized attenuation with the experimental attenuation time series for $19.5 \mathrm{GHz}$ is plotted with respect to time for a rainy event on 13 January, 2004, using an average storm speed of $12.5 \mathrm{~m} / \mathrm{s}$ in Durban as obtained from [8]. The measured rain rate time series and the rain attenuation time series using SST show strong correlation throughout the event (similar pattern). It can also be seen that SST attenuation shows good agreement with the measured data on the frequency considered. However, at attenuation below $5 \mathrm{~dB}$, there is a little disagreement with the observed attenuation. The highest peak attenuation value observed is about $20.3 \mathrm{~dB}$ using SST while it is close to $18.5 \mathrm{~dB}$ based on measured data. This shows a difference of about $1.8 \mathrm{~dB}$ between the two data. Although, the magnitude of the differences depends on the rainy event, the differences may be as a result of little resynchronization between the devices.

Figure 7 also presents the comparison between rain attenuation obtained using the SST model, measured data from 


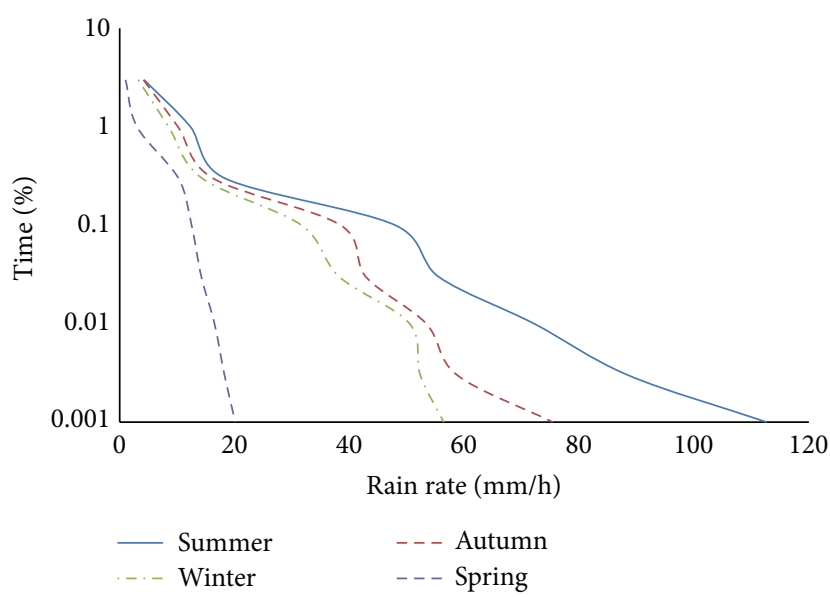

(a)

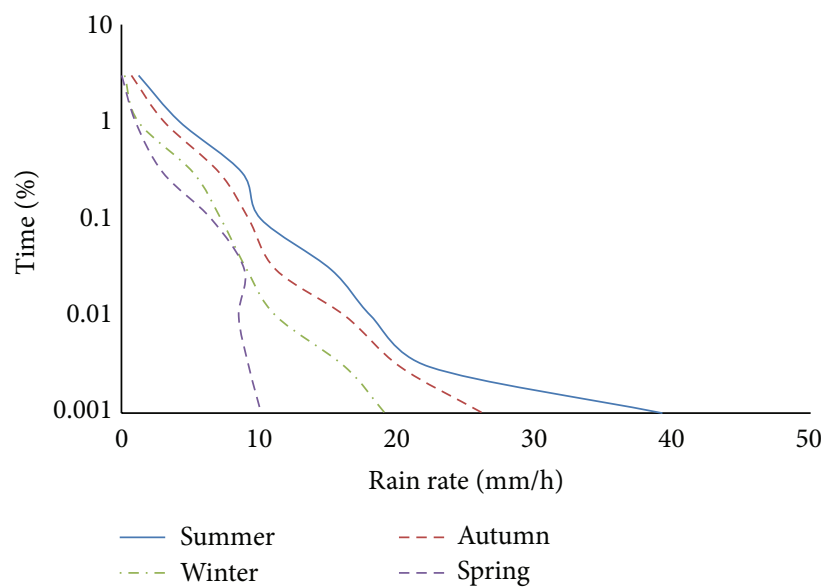

(c)

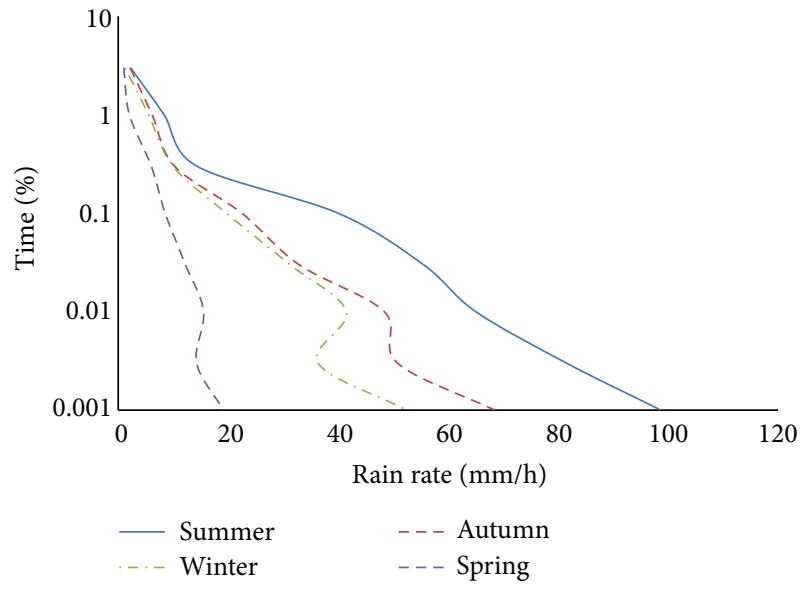

(b)

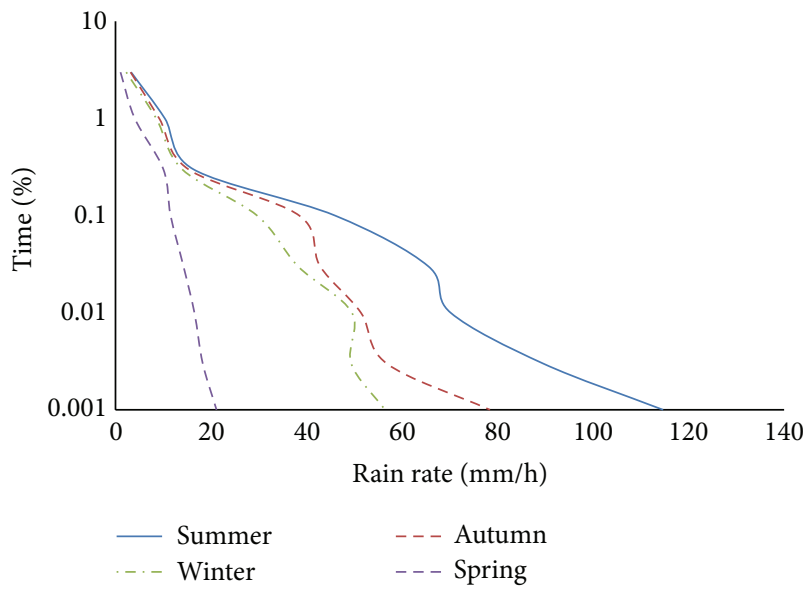

(d)

FIGURE 5: Long term rain rate seasonal exceedance probability at different hours of the day: (a) 0-6 hrs, (b) 6-12 hrs, (c) 12-18 hrs, and (d) $18-24$ hrs.

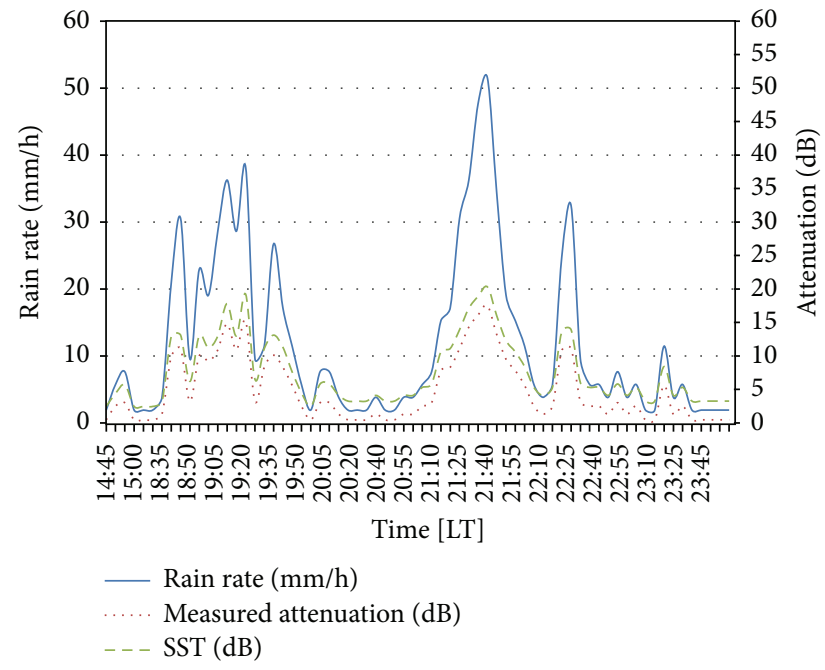

FIGURE 6: Synthesized attenuation using an average storm speed of $12.5 \mathrm{~m} / \mathrm{s}$ with the experimental attenuation time series for $19.5 \mathrm{GHz}$ during a typical rainy event on 13 January, 2004.

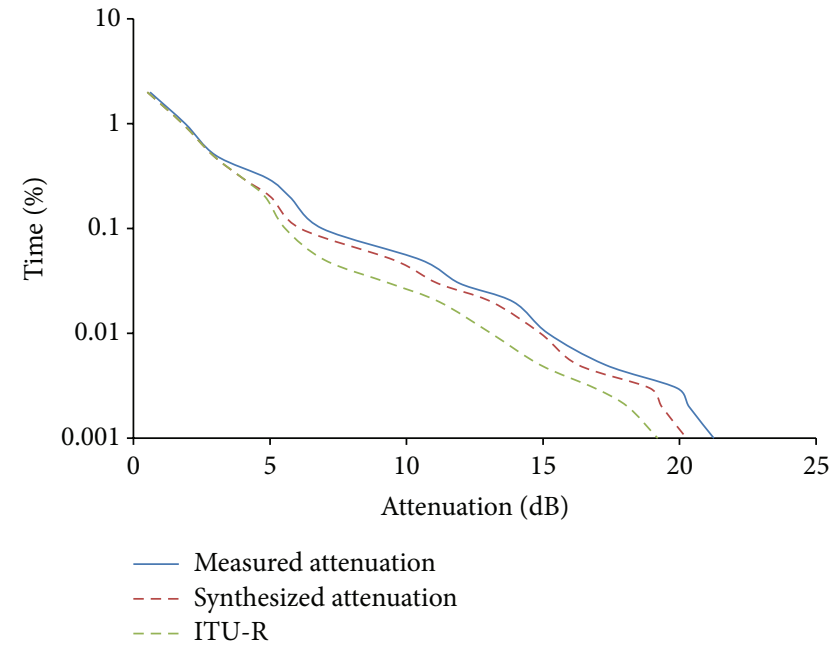

FIGURE 7: Comparison between the measured and predicted signal attenuation in 2004. 


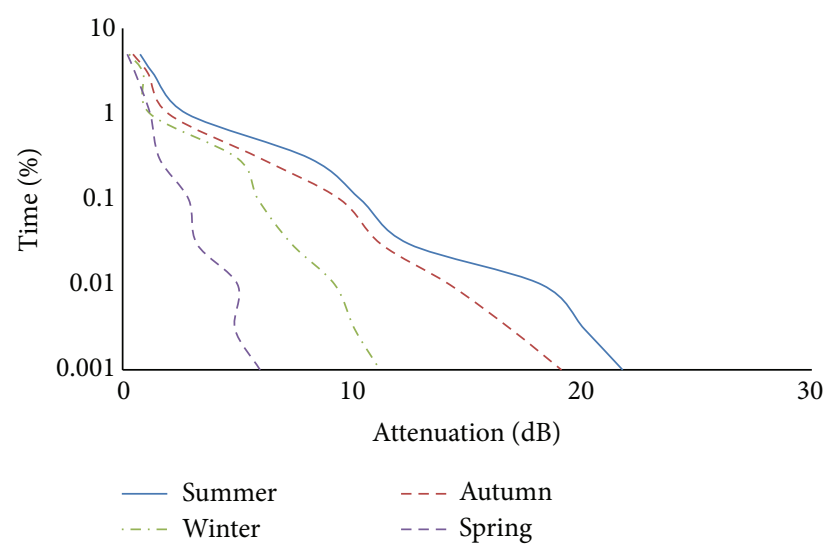

(a)

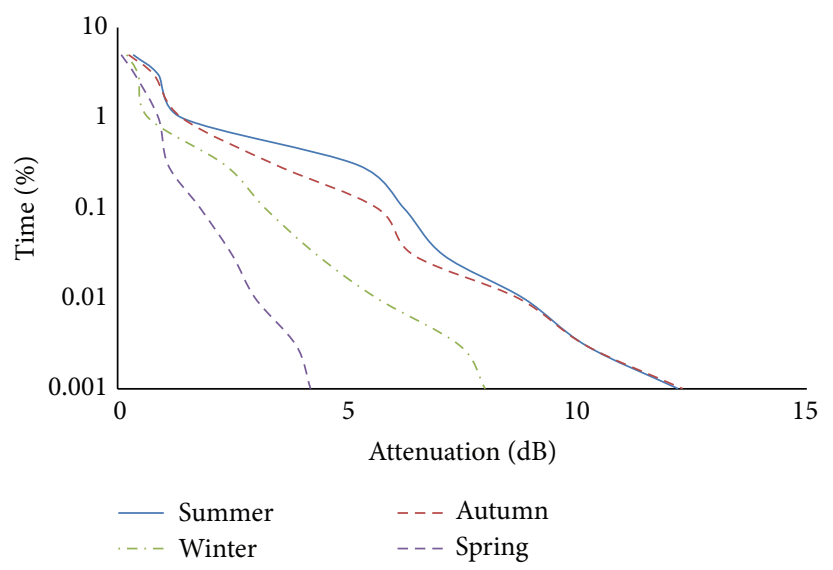

(c)

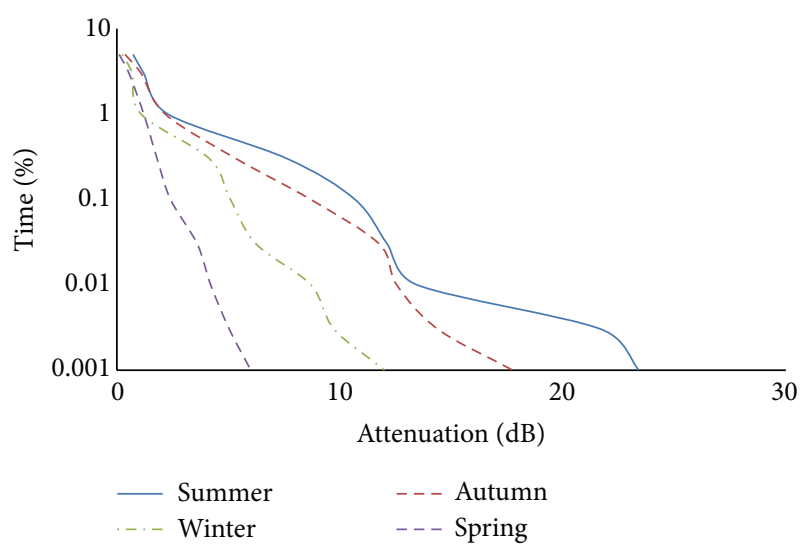

(b)

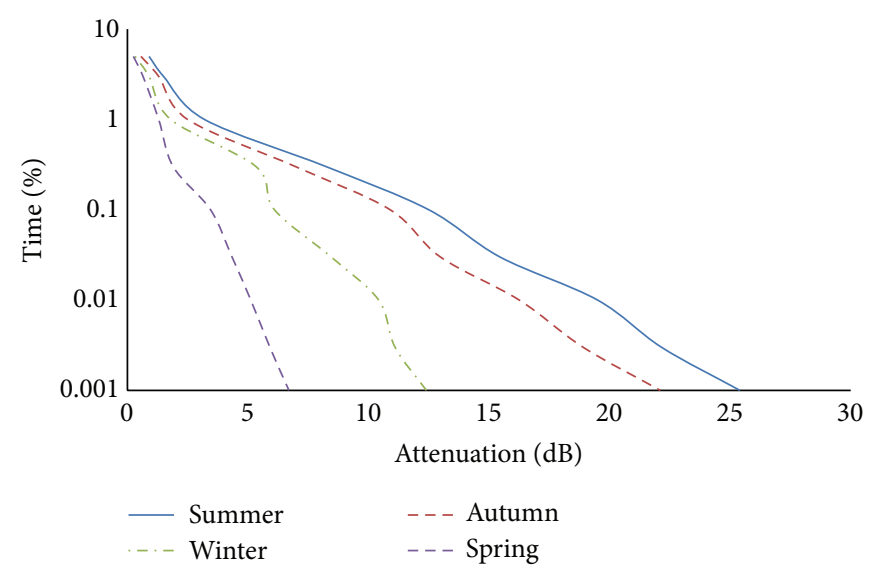

(d)

FIGURE 8: Diurnal variation of synthesized rain attenuation: (a) 0-6 hrs, (b) 6-12 hrs, (c) 12-18 hrs, and (d) 18-24 hrs.

a propagation campaign at Ka-band frequency of $19.5 \mathrm{GHz}$, and the ITU-R 618-10 [25]. It is observed that the SST model provides data very close to the measured attenuation, while the ITU recommendation underestimates the attenuation due to rain in this region. It could also be seen from the plot that measured rain attenuation exceedances match well with the SST as well as ITU values before $4 \mathrm{~dB}$ and overestimated thereafter. Based on one-year measurement, the synthesized attenuation shows peaks lower than those in the measurements to about $-9 \%$ [21], although it is not always the case as reported on the work of $[7,14]$. However, more years of propagation measurement are suggested to ascertain the level of the closeness between the predicted and the measured values of attenuation.

\subsection{Diurnal and Seasonal Variation of Rain Attenuation.} The time-series rain rates have been converted to timeseries rain attenuation using the SST as earlier discussed in Section 3. Figures $8(a)-8(d)$ present a more general view for diurnal rain attenuation, which focuses on the four seasons to deduce the impact of rain rate as it affects attenuation. We observed the same trend as applied to the rain rate pattern earlier discussed in Section 4.2 due to a linear relationship between them with summer season suffering more of raininduced attenuation followed by autumn, winter, and spring. Table 1 summarizes the fade margins to be implemented as a function of the availability of time. We observe that the fade margin to be implemented varies from season to season. For instance, at $99.99 \%$ availability of time needed by most satellite transmission links as recommended by the ITU, the fade margin varies between $5.98 \mathrm{~dB}$ during the spring season and $25.40 \mathrm{~dB}$ in summer season with overall fade margins of $15.34 \mathrm{~dB}$. Although, a fade margin of about $15.34 \mathrm{~dB}$ yields a link availability at $99.99 \%$ averaged over the season, the 99.9\% link availability cannot be achieved during the summer season with only a provision of about $99.6 \%$. That is, the $15.34 \mathrm{~dB}$ would have led to about $114 \mathrm{hr}$ of link outage during the summer seasons in the observed years rather than $29 \mathrm{hr}$ expected. This is a lot of large fade margins needed to be implemented at this high link availability; hence, suitable fade mitigation technique like site diversity needs to be explored [26].

We also plotted (Figure 9) the synthesized rain attenuation for different storm translation speed compared to the measurements at length of $6.73 \mathrm{~km}$ between the two Oregort Scientific WMR928N wireless professional weather stations as reported in [24]. We observed a good matching between 
TABLE 1: Summary of the fade margin to be implemented for all the observed periods on a seasonal basis.

\begin{tabular}{|c|c|c|c|c|c|c|}
\hline Location & Availability & Summer & Autumn & Winter & Spring & Whole season \\
\hline \multirow{6}{*}{ Durban } & $99.99 \%$ & 25.40 & 18.78 & 11.20 & 5.98 & 15.34 \\
\hline & $99.95 \%$ & 22.15 & 17.90 & 11.10 & 5.91 & 14.27 \\
\hline & $99.90 \%$ & 12.50 & 10.90 & 6.10 & 3.45 & 8.24 \\
\hline & $99.50 \%$ & 8.25 & 6.98 & 5.34 & 1.90 & 5.62 \\
\hline & $99.00 \%$ & 3.20 & 2.50 & 1.80 & 1.30 & 2.20 \\
\hline & $95.00 \%$ & 1.50 & 1.30 & 0.90 & 0.65 & 1.09 \\
\hline
\end{tabular}

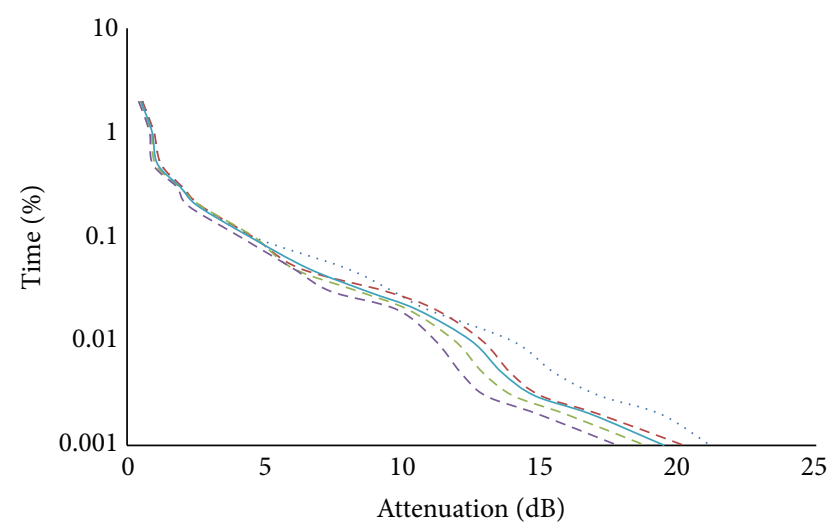

$\begin{array}{ll}\text {.... Prediction } 16 \mathrm{~m} / \mathrm{s} & --- \text { Prediction } 4 \mathrm{~m} / \mathrm{s} \\ \text { - - Prediction } 12 \mathrm{~m} / \mathrm{s} & \quad \text { Measured } \\ --- \text { Prediction } 8 \mathrm{~m} / \mathrm{s} & \end{array}$

FIGURE 9: Cumulative distributions of synthesized attenuation values as a function of storm speed.

the statistics of measured attenuation values and all the predicted values at different speed. This further testified that long term statistics of attenuation range obtained using SST model are almost insensitive to storm speed as reported in the works of $[7,27]$ among others.

\section{Conclusion}

In this paper, synthetic storm technique has been employed for diurnal variation of slant path Ka-band rain attenuation time series in Durban, a subtropical location in South Africa using long term measurement of time-series rain rate. Comparison of measured rain rate data with recent ITU-R shows considerable differences in lower percentages of time with large rain rates (greater than $40 \mathrm{~mm} / \mathrm{h}$ ).

Diurnal and seasonal variation of synthesized attenuation shows that summer season suffered more of rain-induced attenuation followed by autumn, winter, and spring, while 00:00-06:00 GMT and 18:00-24:00 GMT hrs provide more rain attenuation as compared to the other hours of the day. Fade margin to be implemented also varies from season to season. Therefore, applying the same fade margin during each of the seasons may either underestimate or overestimate the required values. Application of our results to a high link availability $(99.99 \%)$ resulted in a large fade margin needed to be implemented; hence, a suitable fade mitigation technique like site diversity may be explored. We also observed that the SST model provides data very close to the measured attenuation and can therefore be used to estimate rain attenuation in this region.

\section{Conflict of Interests}

The authors declare that there is no conflict of interests regarding the publication of this paper.

\section{References}

[1] G. O. Ajayi, S. Feng, S. Radicella, and B. M. Reddy, Eds., Handbook on Radio Propagation Related to Satellite Communication in Tropical and Subtropical Countries, ICTP, Trieste, Italy, 1996.

[2] E. Matricciani, "Physical-mathematical model of the dynamics of rain attenuation based on rain rate time series and a two-layer vertical structure of precipitation," Radio Science, vol. 31, no. 2, pp. 281-291, 1996.

[3] E. Matricciani, "Prediction of fade durations due to rain in satellite communication systems," Radio Science, vol. 32, no. 3, pp. 935-941, 1997.

[4] E. Matricciani, "Diurnal distribution of rain attenuation in communication and brodcasting satellite systems at $11.6 \mathrm{GHz}$ in Italy," IEEE Transactions on Broadcasting, vol. 44, no. 2, pp. 250 258, 1998.

[5] E. Matricciani, "An assessment of rain attenuation impact on satellite communication: matching service quality and system design to the time of the day," Space Communications, vol. 16, no. 4, pp. 195-205, 2000.

[6] E. Matricciani, "Global formulation of the synthetic storm technique to calculate rain attenuation only from rain rate probability distributions," in Proceedings of the IEEE Antennas and Propagation Society International Symposium (AP-S '08), pp. 1-4, IEEE, San Diego, Calif, USA, July 2008.

[7] D. Das and A. Maitra, "Time series prediction of rain attenuation from rain rate measurement using synthetic storm technique for a tropical location," International Journal of Electronics and Communications, vol. 68, pp. 33-36, 2014.

[8] "South Africa Weather," http://www.sa-venues.com/no/weather .htm.

[9] P. A. Owolawi, "Rainfall rate probability density evaluation and mapping for the estimation of rain attenuation in South Africa and surrounding islands," Progress in Electromagnetics Research, vol. 112, pp. 155-181, 2011.

[10] H. N. Kheirallah, B. Segal, and R. L. Olsen, "Application of synthetic storm data to evaluate simpler techniques for predicting rain attenuation statistics," Annales Des Télécommunications, vol. 35 , no. 11-12, pp. 456-462, 1980. 
[11] E. Matricciani and C. Riva, "The search for the most reliable long-term rain attenuation $\mathrm{CDF}$ of a slant path and the impact on prediction models," IEEE Transactions on Antennas and Propagation, vol. 53, no. 9, pp. 3075-3079, 2005.

[12] S. A. Kanellopoulos, A. D. Panagopoulos, E. Matricciani, and J. D. Kanellopoulos, "Annual and diurnal slant path rain attenuation statistics in Athens obtained with the synthetic storm technique," IEEE Transactions on Antennas and Propagation, vol. 54 , no. 8 , pp. 2357-2364, 2006.

[13] J. D. Kanellopoulos and P. Kafetzis, "Comparison of the synthetic storm technique with a convectional rain attenuation prediction model," IEEE Transactions on Antennas and Propagation, vol. 34, no. 5, pp. 713-715, 1986.

[14] I. Sánchez-Lago, F. P. Fontán, P. Marino, and U.-C. Fiebig, "Validation of the synthetic storm technique as part of a timeseries generator for satellite links," IEEE Antennas and Wireless Propagation Letters, vol. 6, pp. 372-375, 2007.

[15] G. Drufuca, "Rain attenuation statistics for frequencies above $10 \mathrm{GHz}$ from rain gauge observations," Journal de Recherches Atmospheriques, vol. 8, pp. 399-411, 1974.

[16] ITU-R P.838-3, Specific Attenuation Model for Rain for Use in Prediction Methods, International Telecommunication Union, Geneva, Switzerland, 2005.

[17] D. Maggiori, "Computed transmission through rain in the 1$400 \mathrm{GHz}$ frequency range for spherical and elliptical drops and any polarization," Alta Frequenza, vol. 50, no. 5, pp. 262-273, 1981.

[18] ITU-R, "Characterizations of precipitationfor propagation modeling height Model for prediction methods Recommendation P," ITU-R Ser. ITU-R P.839-5, International Telecommunication Union, Geneva, Switzerland, 2005.

[19] A. A. Alonge and T. J. Afullo, "Seasonal analysis and prediction of rain-fall effects in Eastern South Africa at microwave frequencies," Progress in Electromagnetics Research B, no. 40, pp. 279-303, 2012.

[20] M. O. Fashuyi, P. A. Owolawi, and T. J. Afullo, "Rainfall rate modeling for Los radio systems in south Africa," SAIEE Africa Research Journal, vol. 97, no. 1, pp. 74-81, 2006.

[21] ITU-R P. 311-12, "Acquisition, presentation and analysis of data in studies of tropospheric propagation," Recommendations, 2005.

[22] ITU-R.P837-1,2,3,4,5, Characteristics of Precipitation for Propagation Modelling, Vol . 1992-2003, P Series, International Telecommunication Union, Geneva, Switzerland, 1992.

[23] S. Das, A. Maitra, and A. K. Shukla, "Diurnal variation of slant path ka-band rain attenuation at four tropical locations in India," Indian Journal of Radio and Space Physics, vol. 42, no. 1, pp. 34-41, 2013.

[24] M. O. Fashuyi and T. J. Afullo, "Rain attenuation prediction and modeling for line-of-sight links on terrestrial paths in South Africa," Radio Science, vol. 42, no. 5, Article ID RS5006, 2007.

[25] ITU-R P.618-10, "Propagation data and prediction methods required for the design of Earth-space telecommunication systems," Tech. Rep. ITU-R Ser, International Telecommunication Union, Geneva, Switzerland, 2010.

[26] U.-C. Fiebig and C. Riva, "Impact of seasonal and diurnal variations on satellite system design in V band," IEEE Transactions on Antennas and Propagation, vol. 52, no. 4, pp. 923-932, 2004.

[27] E. Matricciani, C. Riva, and L. Castanet, "Performance of the synthetic storm technique in a low elevation $5^{\circ}$ slant path at $44.5 \mathrm{GHz}$ in the French Pyrénées," in Proceedings of the 1st European Conference on Antennas and Propagation (EuCAP '06), Nice, France, November 2006. 

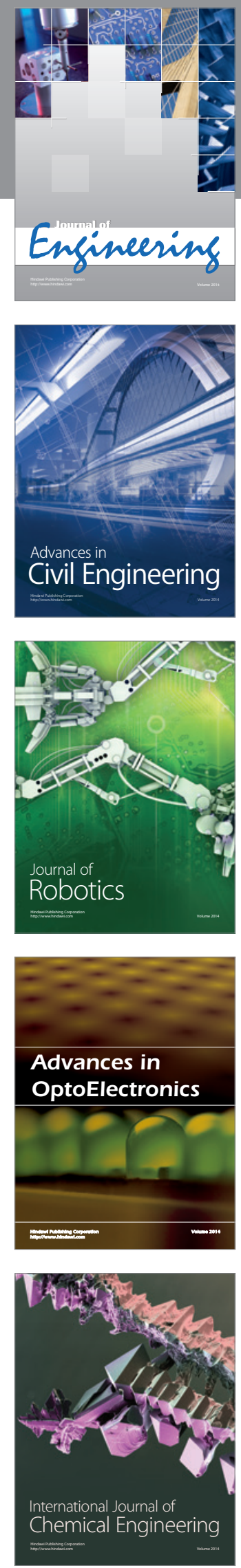

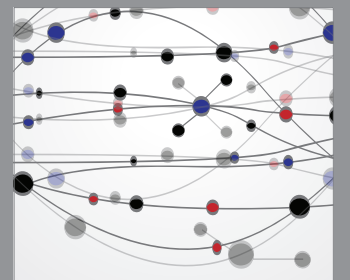

The Scientific World Journal
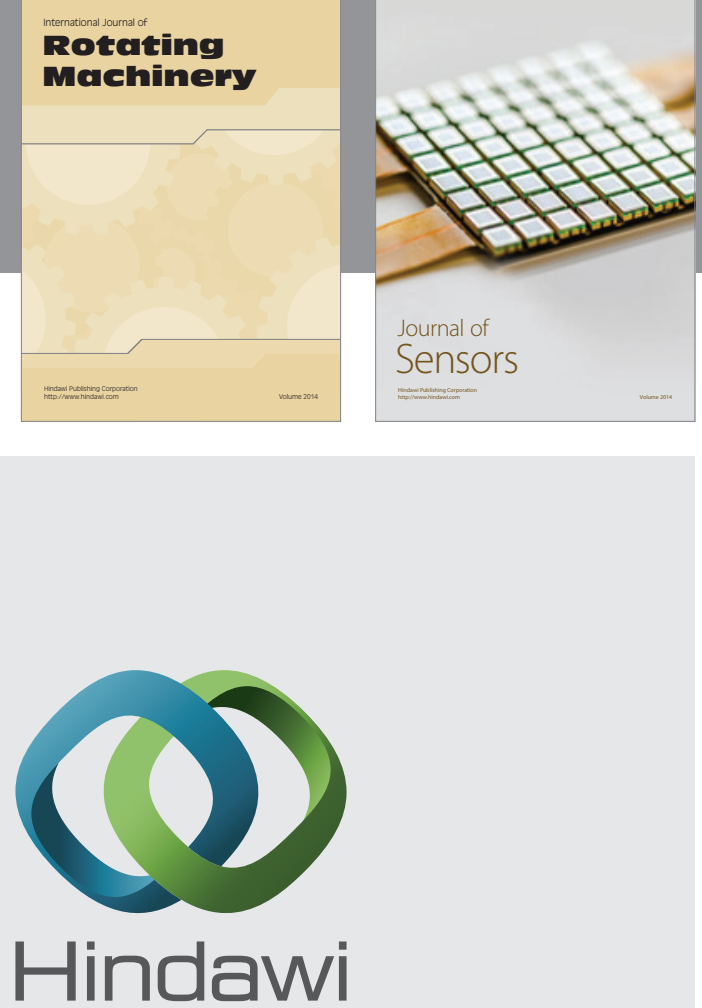

Submit your manuscripts at http://www.hindawi.com
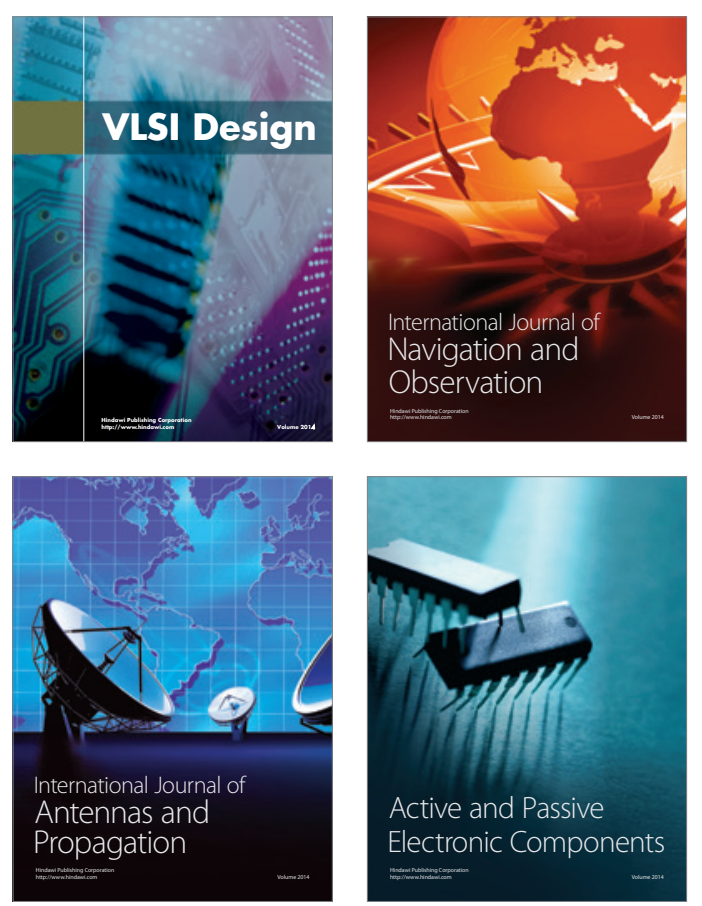
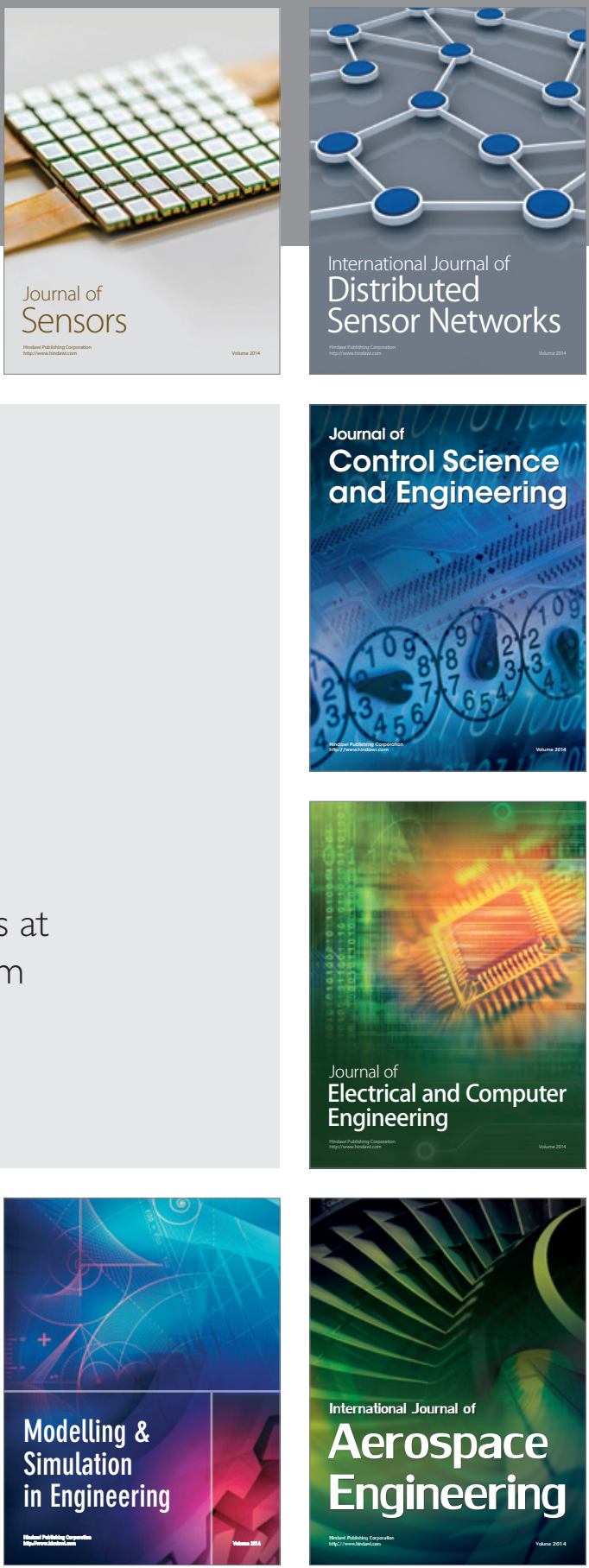

Journal of

Control Science

and Engineering
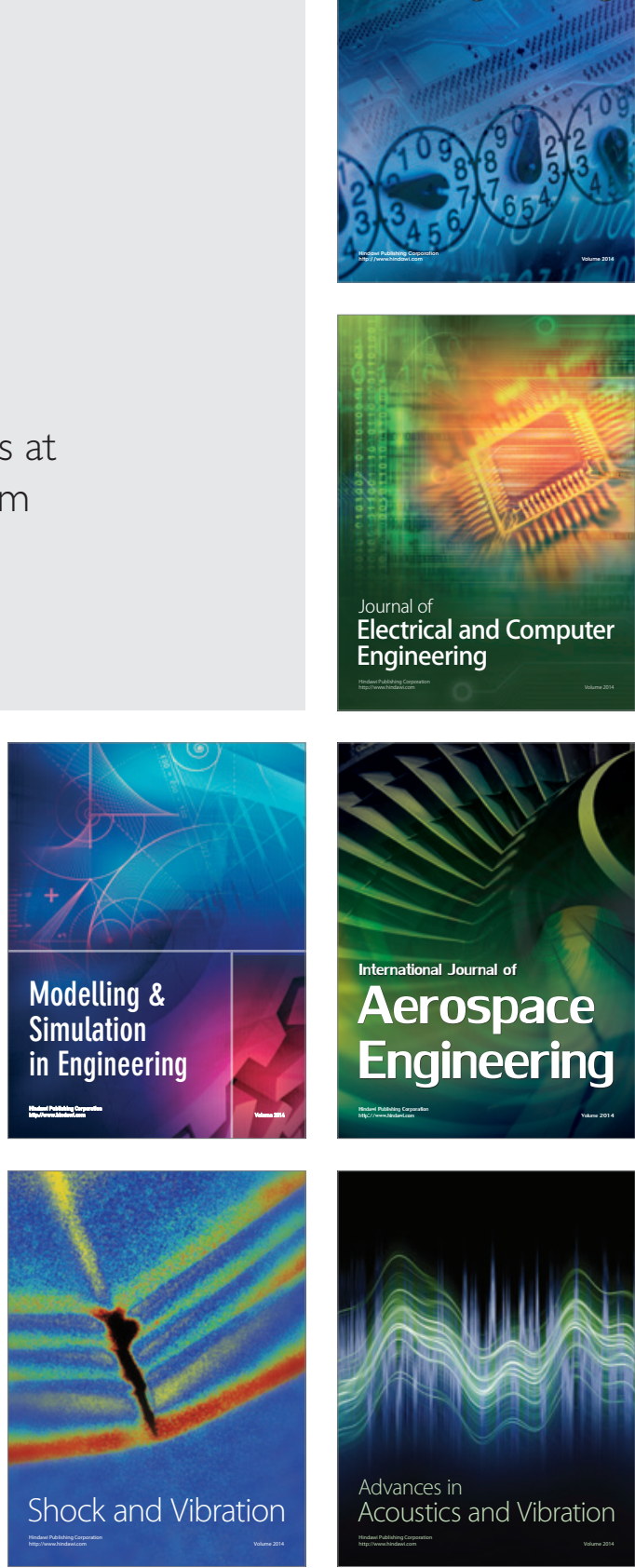